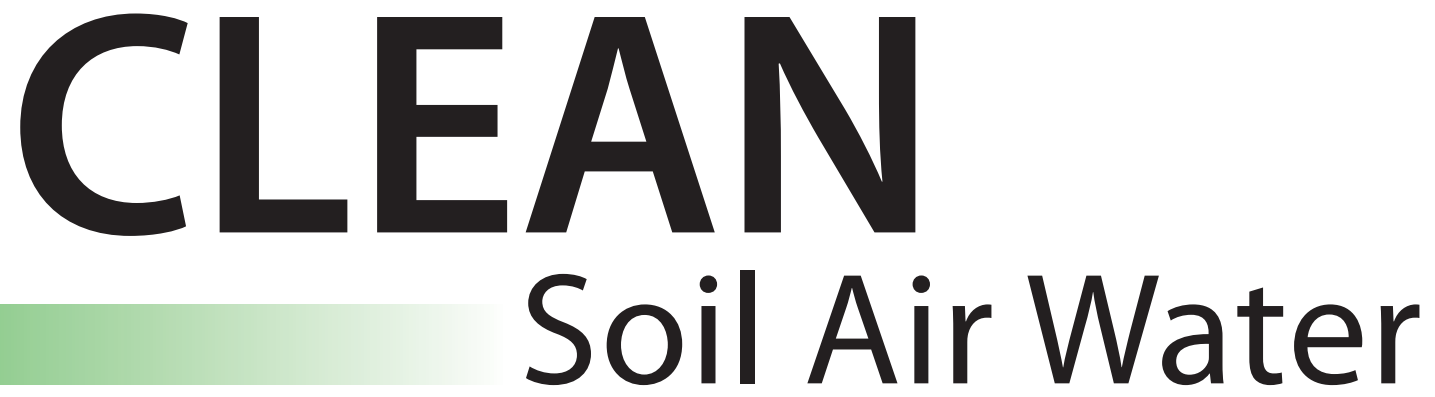

Renewables

Sustainability

Environmental Monitoring

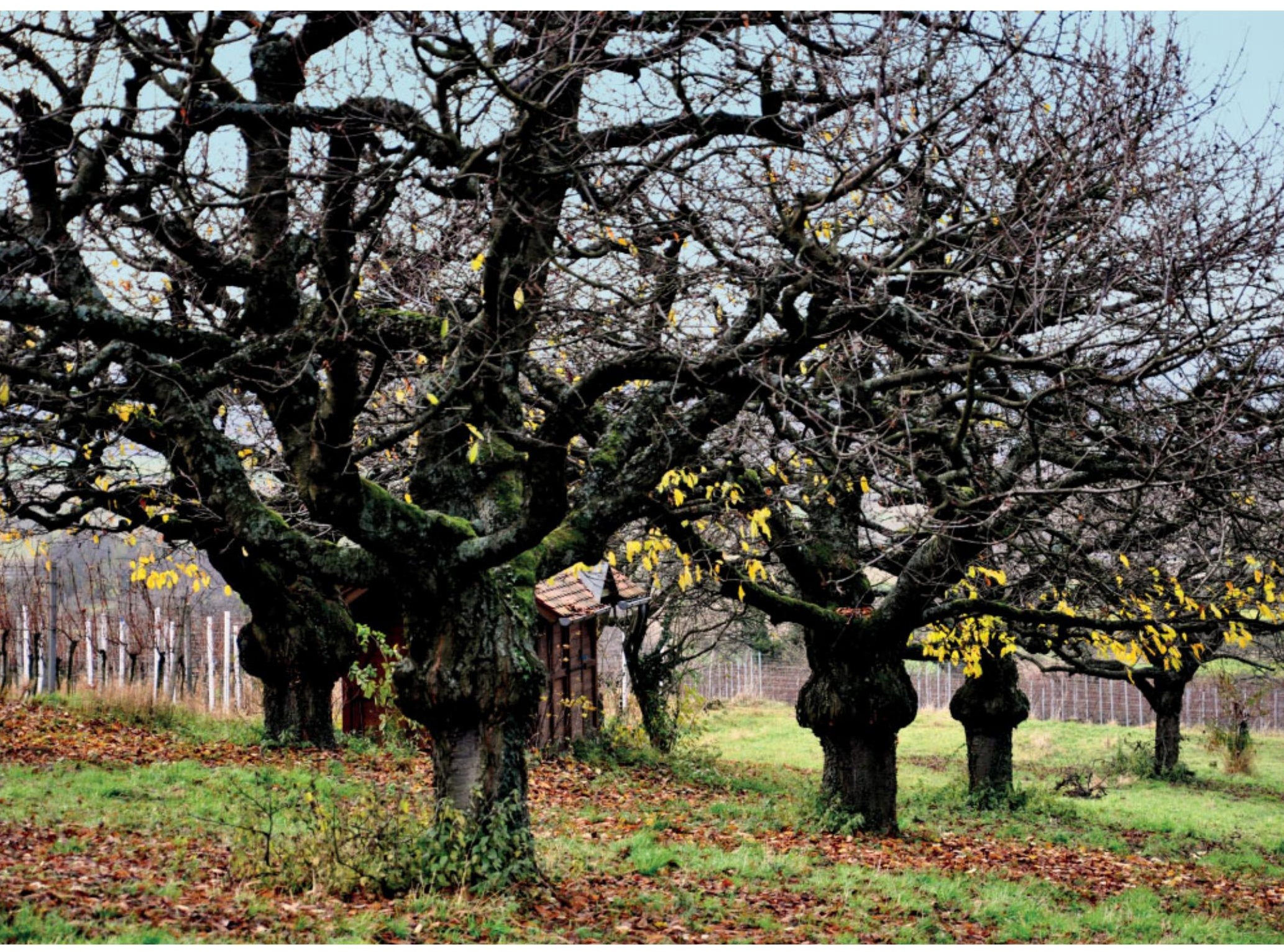




\author{
Xinzhong $\mathrm{Du}^{1,2}$ \\ Jingjun $\mathrm{Su}^{1}$ \\ Xuyong $\mathrm{Li}^{1}$ \\ Wangshou Zhang ${ }^{1,2}$ \\ ${ }^{1}$ State Key Laboratory of Urban and \\ Regional Ecology, Research Center \\ for Eco-Environmental Sciences, \\ Chinese Academy of Sciences, \\ Beijing, China \\ ${ }^{2}$ University of Chinese Academy of \\ Sciences, Beijing, China
}

\section{Research Article \\ Modeling and Evaluating of Non-Point Source Pollution in a Semi-Arid Watershed: Implications for Watershed Management}

\begin{abstract}
Watershed models are cost-effective and powerful tools for evaluating and controlling nonpoint source (NPS) pollution. Generalized Watershed Loading Functions (GWLF) model, a relative parsimonious model, was applied to simulate watershed streamflow and nutrient loads in Liu River watershed, northern China. The model results were used to evaluate watershed NPS load, and the implications for NPS pollution mitigation measures were investigated. The temporal-spatial distribution, the critical source areas (CSAs) at subwatershed level, and the best management practices (BMPs) efficiencies at CSAs were investigated by GWLF model. Due to the contrasting hydrological conditions, the NPS loads of wet year and flood season were much more than those of dry year and non-flood season. Four sub-watersheds were identified as CSAs, and the results showed that CSAs had high level of load intensities due to the high percentage of agricultural land and residential land. Through evaluating the efficiency and cost of seven BMPs, conservation tillage and vegetative buffers were selected as the measures to implement in the CSAs, and they can reduce $14.2 \%$ and $12.5 \%$ of total nitrogen and total phosphorus NPS loads in Liu river watershed. These findings can provide valuable information for implementing more effective and reasonable management measures to control NPS pollution in Liu River watershed and indicate the utility of GWLF with modest data requirements for such application.
\end{abstract}

Keywords: Best management practices; Critical source areas; GWLF model; Nutrient load; Temporal-spatial distribution

Received: November 5, 2014; revised: February 9, 2015; accepted: April 5, 2015

DOI: $10.1002 /$ clen.201400773

\section{Introduction}

Nutrients (primarily nitrogen $[\mathrm{N}]$ and phosphorus $[\mathrm{P}]$ ) are essential for plant and animal life, but in high concentrations can cause a number of environmental and ecological problems including water quality degradation algal blooms, decreased dissolved oxygen concentrations, and increased fish mortality [1]. The cumulative increases in $\mathrm{N}$ and $\mathrm{P}$ loads in receiving water bodies are commonly attributed to human activities [2,3]. The anthropogenic disturbances that supply excess nutrients which can be export to the receiving water bodies would deteriorate the water quality, and non-point source (NPS) is the important pathway for nutrient export. As point source pollution has gradually been under control in recent years, NPS pollution, especially agricultural NPS, has become a major contributing factor to water pollution in China [4]. The contribution of NPS pollution to total water pollution in China was estimated to

Correspondence: Professor X. Li, State Key Laboratory of Urban and Regional Ecology, Research Center for Eco-Environmental Sciences, Chinese Academy of Sciences, Beijing 100085, China

E-mail: Xyli@rcees.ac.cn

Abbreviations: BMP, best management practice; CSA, critical source area; GWLF, generalized watershed loading function; HSPF, Hydrological Simulation Program-Fortran; NPS, non-point source; NSE, Nash-Sutcliff coefficient; PRedICT, pollution reduction impact comparison tool; RE, relative error; RMSE, root mean square error; SWAT, soil and water assessment tool; TN, total nitrogen; TP, total phosphorusz be $81 \%$ for $\mathrm{N}$ and $93 \%$ for $\mathrm{P}$ [5]. Currently, field studies and modeling techniques are two feasible approaches in evaluating NPS pollution [6]. Monitoring NPS pollution on site is very difficult because they originate from spatially and temporally varying areas. Therefore, it is seldom possible to accurately pinpoint the NPS pollution using water quality monitoring programs. Meanwhile, the monitoring programs often require long-term continuous monitoring to account for the variations of hydrological and climatic conditions. However, watershed model are cost-effective and powerful tools to evaluate and investigate the NPS pollution.

The temporal-spatial distribution of NPS pollution can provide significant information on when and where to implement the management practices to reduce pollutant load efficiently, which is very useful for designing the nutrient load reduction programs. Since the critical source areas (CSAs) often contribute the greatest pollution load to a watershed and have high pollution load intensities, CSAs identification has become an important and necessary process for efficient NPS control [7]. Prioritizing the pollution control in CSAs would not only reduce the pollution load efficiently, but also use the limited environmental protection funds more economically. Identifying CSAs within a watershed and implementing best management practices (BMPs) in those areas has been recommended in previous studies [8], and this procedure can enable policy makers to allocate monetary resources in an efficient way [9]. Previous studies had used watershed models to investigate temporal-spatial distribution of NPS pollution [10], to 
identify CSAs within a watershed [11], and to evaluate the BMP efficiencies [12]. The complexities and input data requirements of the models used are different, and very few studies have simultaneously investigated temporal-spatial distribution, CSAs identification, and BMP efficiencies with one single model. Parsimonious modeling techniques, which require modest amounts of data to evaluate the responses of watershed NPS pollution to varying temporal-spatial conditions and typical management practices, are especially valuable for Chinese watershed environmental management [13]. Complex models, such as soil and water assessment tool (SWAT) and Hydrological Simulation ProgramFortran (HSPF), have intensive input and calibration data requirements, which limit their applicability for the watersheds with limited data sources, a situation found in many regions of China and the developing world. Moreover, complex models usually increase parameter numbers and uncertainty and do not necessarily improve the model performance [14]. The Generalized Watershed Loading Functions (GWLF) model can be seen as a compromise between an empirical statistical model and a complex mechanistic model, and this model is capable of simulating most of the key mechanisms controlling nutrient fluxes within a watershed. This model is relatively easy to use and needs less input data than those required by SWAT and HSPF. In this study, the GWLF model was selected to simulate watershed streamflow and nutrient load, and then to evaluate the NPS pollution load based on the model results. The objectives of this study were: (1) to investigate temporal and spatial distribution of NPS nutrient load; (2) to identify CSAs at sub-watershed level; and (3) to evaluate the efficiencies of selected BMPs in CSAs.

\section{Materials and Methods}

\subsection{Study Area}

The Liu River watershed (Fig. 1) is situated in the northeast of Hebei province in northern China and is a typical sub-basin of the Luan

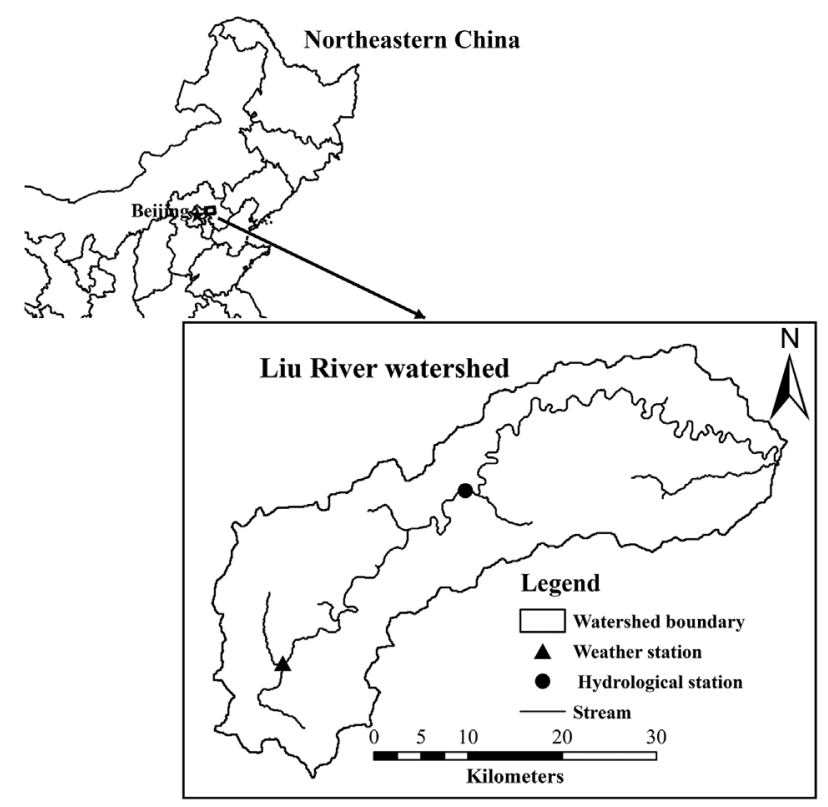

Figure 1. Location of the study watershed, weather station, and hydrological station.
River catchment. The water of the Liu River watershed flows directly into the Panjiakou reservoir, which is the main drinking water source area of the Tianjin and Tangshan city. It is a semi-arid region with an annual mean temperature of $8.4^{\circ} \mathrm{C}$ and an annual mean precipitation of $650 \mathrm{~mm}$. The flood season is from June to October, during which time between 60 and $70 \%$ of the annual precipitation occurs. The study catchment is mountainous and covers an area of approximately $1169 \mathrm{~km}^{2}$. The elevation ranges from 224 to $1924 \mathrm{~m}$, and the average slope is $12 \%$. The land uses map is given in Fig. 2, and the dominant land use is forest, which accounts for $58.9 \%$ of the catchment area. Other land uses include agricultural land (5.7\%), orchards $(9.8 \%)$, grassland $(18.5 \%)$, water $(1.5 \%)$, and settlements (5.6\%). One hydrological station named Liying is located in the middle part of Liu River and controlled a draining area of $626 \mathrm{~km}^{2}$ (Fig. 1).

\subsection{The GWLF Model}

GWLF is a lumped watershed model that can simulate monthly streamflow, sediment, and nutrient loads [15]. Streamflow consists of surface and groundwater runoff. GWLF uses the soil conservation service curve number approach to calculate surface runoff from different land uses. The groundwater runoff is obtained from a lumped parameter watershed water balance. Erosion is computed using the universal soil loss equation and the sediment yield is the product of erosion and the sediment delivery ratio. The streamflow nutrient flux comprises dissolved and solid phases in the GWLF model. Dissolved nutrients are associated with surface runoff, point sources, and groundwater discharge, while solid-phase nutrients are associated with point sources, soil erosion, or runoff from impervious urban surface. Dissolved loads from each source area are calculated as multiplying runoff by dissolved concentrations, and dissolved concentrations of groundwater and surface runoff for different land uses were the model parameters. Solid-phase nutrient loads from rural areas are given by as the product of the monthly sediment yields and the average sediment nutrient concentrations, and those from urban area are modeled by exponential accumulation and wash off functions. The GWLF model describes NPSs using a distributed model for runoff, erosion, and urban runoff, and a lumped parameter linear reservoir model for groundwater. Nutrient loads from point sources are added as a constant mass load to the

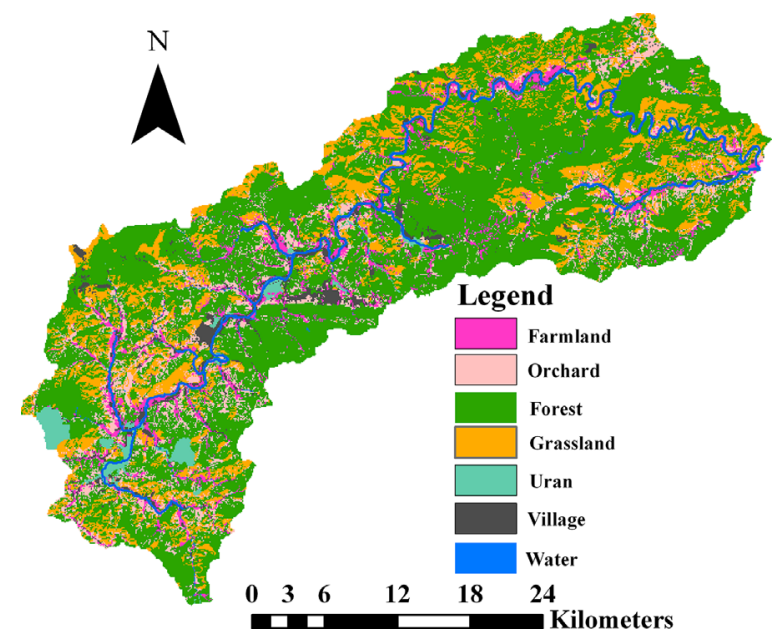

Figure 2. The land uses map of the Liu River watershed. 
simulated NPS load to provide the total load from the watershed. More details about the model calculation can be found in the GWLF model manual.

\subsection{Data Preparation and Model Calibration Process}

The data used for GWLF model simulation can be divided into three categories: the spatial data, meteorological data, observed streamflow, and nutrient concentration data. The spatial and meteorological data were used as input data to drive the model. The spatial data were the digital elevation model (DEM), land use and soil map, and the meteorological data were daily mean air temperature and daily precipitation. Daily mean temperature data of the Xinglong station and daily precipitation data from the Xinglong and Liying stations in the watershed were used. Besides, the point source loads from the 12 sewage outlets ( 132 tons TN/year and 3.6 tons TP/year) within the watershed were used as the model input data. Streamflow and water quality data from the Liying hydrological station were used for model calibration and validation. The monthly nutrient concentrations were multiplied by the average monthly streamflow to estimate the monthly nutrient loads. Types, sources, and descriptions of the data used in the GWLF model can be seen from Du et al. [16].

The Liu watershed was divided into 18 sub-watersheds, and nine of them were above the Liying hydrological station. The model parameters of Liu watershed were calibrated using the data from Liying hydrological station, and the calibrated parameters were used to estimate the nutrient loads of sub-watersheds down the station. The calibration period was from 2004 to 2007, while the validation period was from 2008 to 2011. The data of 2003 were used as a "warm up" period to minimize the impact of initial condition errors. Hydrological parameters were estimated by comparing simulated streamflow to monthly observed value. Once the hydrological parameters were calibrated, sediment and nutrient parameters were calibrated by comparing model simulation to estimated monthly nutrient loads. The values for each parameter to be calibrated must be in a range based either on existing literature or watershed characteristics [17]. The ranges of calibrated parameters were derived from a previous study in this watershed [16], and the ranges were determined by watershed characteristics or previous literature. For instance, the initial curve numbers were given based on land uses and soil groups, and the ranges of particulate nutrient concentrations in sediment were determined by the nutrient concentrations in soil and the enrichment ratio. However, the ranges of dissolved nutrient concentrations in surface runoff for different land uses were from the field studies around the study watershed. Once the parameter ranges were determined, we used a Monte Carlo sampling approach to generate one million parameter sets for calibration, from which we selected the parameter set with the minimum objective function value as the optimal parameter set. In this study, the root mean square error (RMSE) was used as the objective function, and the relative error (RE), Nash-Sutcliff coefficient (NSE), and coefficient of determination $\left(R^{2}\right)$ were used as measures of model performance, and are defined as follows:

RMSE $=\sqrt{\frac{\sum_{t=1}^{n}\left(y_{\text {sim }}^{t}-y_{\text {obs }}^{t}\right)^{2}}{n}}$
$\mathrm{RE}=\frac{\sum_{t=1}^{n}\left(y_{\text {sim }}^{t}-y_{\mathrm{obs}}^{t}\right)}{\sum_{t=1}^{n} y_{\mathrm{obs}}^{t}} \times 100 \%$

$$
\begin{aligned}
& \mathrm{NSE}=1 \frac{\sum_{t=1}^{n}\left(y_{\mathrm{sim}}^{t}-y_{\mathrm{obs}}^{t}\right)^{2}}{\sum_{t=1}^{n}\left(y_{\mathrm{obs}}^{t}-\overline{y_{\mathrm{obs}}}\right)^{2}} \\
& R^{2}=\frac{\sum_{t=1}^{n}\left(y_{\mathrm{sim}}^{t}-\overline{y_{\text {sim }}}\right)\left(y_{\mathrm{obs}}^{t}-\overline{y_{\mathrm{obs}}}\right)}{\sqrt{\sum_{t=1}^{n}\left(y_{\mathrm{sim}}^{t}-\overline{y_{\mathrm{sim}}}\right)^{2} \sum_{t=1}^{n}\left(y_{\mathrm{sim}}^{t}-\overline{y_{\mathrm{sim}}}\right)^{2}}}
\end{aligned}
$$

where $y_{\text {sim }}^{t}$ is the monthly simulated value in month $t, y_{\text {obs }}^{t}$ is the observed value in month $t, \overline{y_{\text {sim }}}$ is the mean observed value for the simulated period, and $\overline{y_{\mathrm{obs}}}$ is the mean simulated value of the simulated period.

\subsection{The Temporal-Spatial Distribution of NPS Load and Identification of CSAs}

The NPS load is the total streamflow load minus point sources in this study. The temporal distribution was investigated based on the model estimated NPS load of the whole watershed. The Liu River watershed was divided into 18 sub-watersheds, and the areas of these subwatersheds ranged from 30.4 to $120 \mathrm{~km}^{2}$. The parameters of the GWLF model were calibrated using the observed data at Liying gauge station, and the NPS load for each sub-watershed was estimated by the calibrated parameters. Then, the temporal distribution was analyzed on the sum of NPS loads in 18 sub-watersheds. The temporal distribution was evaluated at annual, seasonal (flood and non-flood seasons) and monthly scale. The identification of CSAs was based on the load intensities (load per unit area) and cumulative percent of the total NPS loads. Maps were created based on the load intensities of each sub-watershed to depict the CSAs separately for TN and TP using the GWLF model simulation results. To identify the CSAs, sub-watersheds were ranked in descending order based on the load intensities. The subwatershed with the highest load intensity ranked first and the one with the lowest ranked last. Afterwards, moving from the highest ranking to the lowest, sub-watersheds collectively contribute greater than the selected threshold percentage of the total NPS load were identified as CSAs $[11,18]$. The $30 \%$ threshold is an arbitrary choice, and the purpose here, was to demonstrate the GWLF model for CSAs identification. The actual threshold is a function of the cost of implementing management practices and water quality improvement targets [18]. For instance, if there is enough money for implementation of management practices and more strict water quality improvement target, a higher threshold is needed. Therefore, moving from the highest ranking to the lowest based on load intensities, sub-watersheds that collectively contribute more than $30 \%$ of the total NPS loads were identified as CSAs in this study.

\section{Results and Discussion}

\subsection{Model Performance of Streamflow, and TN and TP Loads}

Figure 3 shows the comparisons between the simulated and observed data. The visual comparisons indicated that GWLF could 

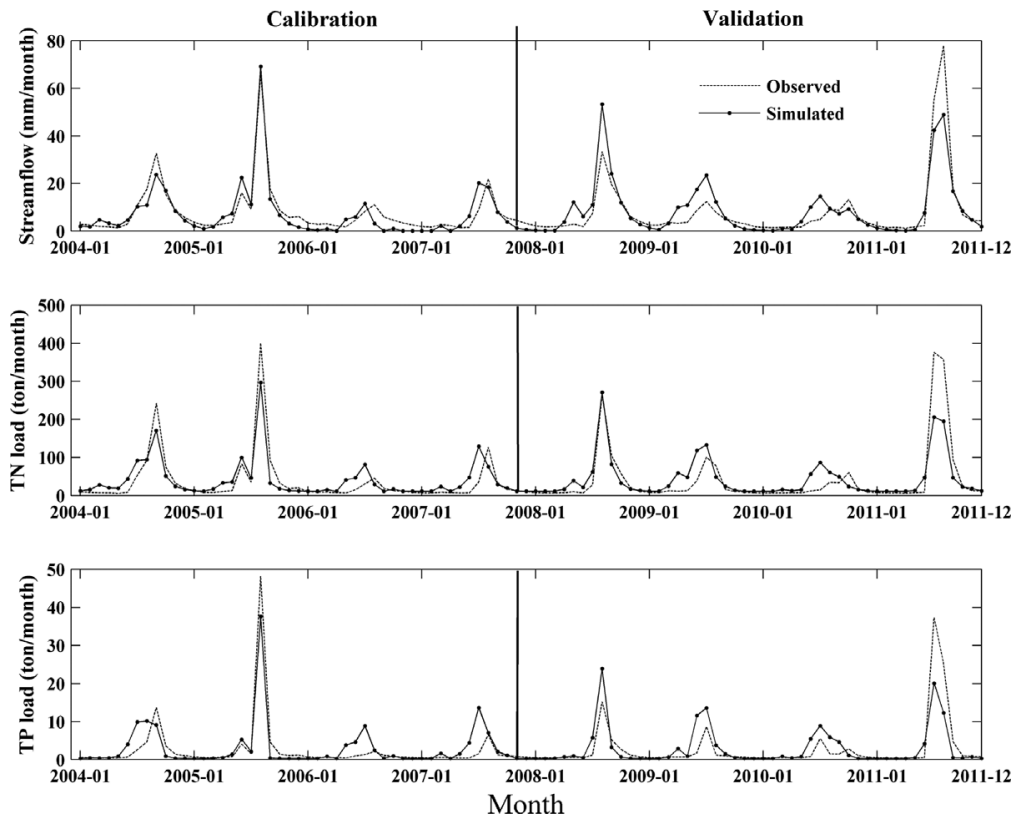

Figure 3. Observed and simulated monthly streamflow, TN, and TP load for Liying gauge station.

provide acceptable simulations because the model predictions follow a similar trend to the observed data and could capture the seasonal and monthly variations within the reasonable ranges. For streamflow, RE, $R^{2}$, and NSE of monthly streamflow were $-9.0 \%, 0.88$, and 0.82 , respetcively, during the calibration period, and were $7.8 \%$, 0.77 , and 0.76 , respetcively, during the validation period. Although the simulated peak streamflow was underestimated for a small number of high flow periods, as in August 2011, the performance of
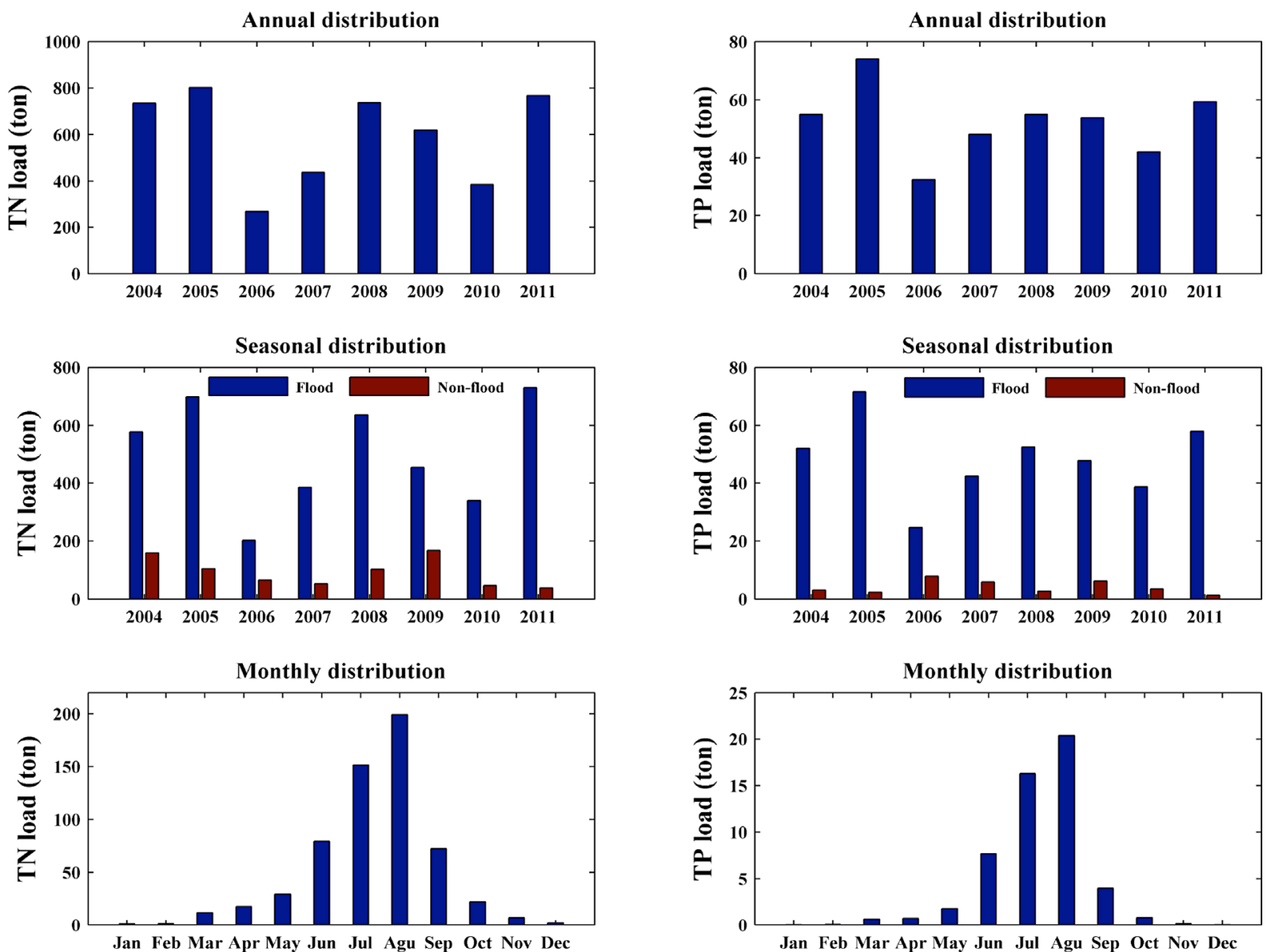

Figure 4. Multi-scale temporal (annual, seasonal, and monthly) distribution of NPS load. 
the simulated monthly streamflow was overall good. For the monthly TN load, RE, $R^{2}$, and NSE were $6.2 \%, 0.82$, and 0.76 , respectively, during the calibration period, and $9.3 \%, 0.79$, and 0.62 , respectively, during the validation period. For the monthly TP load, RE, $R^{2}$, and NSE were $9.8,0.67$, and $0.65 \%$, respectively, during the calibration period, and were $5.2 \%, 0.62$ and 0.66 , respectively, during the validation period. Overall, the agreement between the monthly simulated and observed data for the TN and TP load was acceptable; despite of that the simulated peak values were obviously underestimated for high flow periods in flood season, as in August 2008. The GWLF model is a continuous model with daily step, it tends to underestimate streamflow, sediment, and nutrient loads for months which contain short intense storm events. For instance, peak monthly nutrient load were underestimation up to $35 \%$ in the validation study by the model developers, and they pointed out that the underestimation of peak monthly values was one of GWLF model's limitations [15].

\subsection{Multi-Scale Temporal Distribution of NPS Load}

Figure 4a shows the annual distributions of TN and TP NPS load, and the NPS loads obviously displayed variations among different years. The maximum TN load was 802.6 ton/year in 2005, and minimum load was 266.7 ton/year in 2006. These 2 years represented typical wet and dry years during the simulation period. The water components of the GWLF model simulation in 2005 and 2006 are presented in Fig. 5a, and the results showed that the rainfall, streamflow, surface-runoff, and baseflow in 2005 were higher compared with 2006. Since the NPS load export is driven by rainfallrunoff events in this watershed, the greater rainfall and runoff in the wet year resulted in a higher NPS load export than in the dry year. This was in agreement with the findings of Aguilera et al. [19] who showed that NPS loads of TN and TP were higher in wet years compared to dry years.

The seasonal and monthly distribution of NPS loads is shown in Fig. $4 \mathrm{~b}$ and $\mathrm{c}$. The results indicated that the NPS TN and TP loads during the flood season accounted for the vast majority of their annual load (83.9\% for TN and $91 \%$ for TP on average). As shown in Fig. 4c, the monthly distribution of the NPS load followed a similar pattern with the seasonal distribution. The months during the flood season accounted for the vast majority of annual NPS load, especially in July and August. The NPS loads for TN and TP during July and August accounted for 59 and $70 \%$ of TN and TP annual loads, respectively. In order to investigate the reason for the seasonal variation of NPS loads, the monthly water balance components (rainfall, streamflow, surface runoff, baseflow, and

(a)

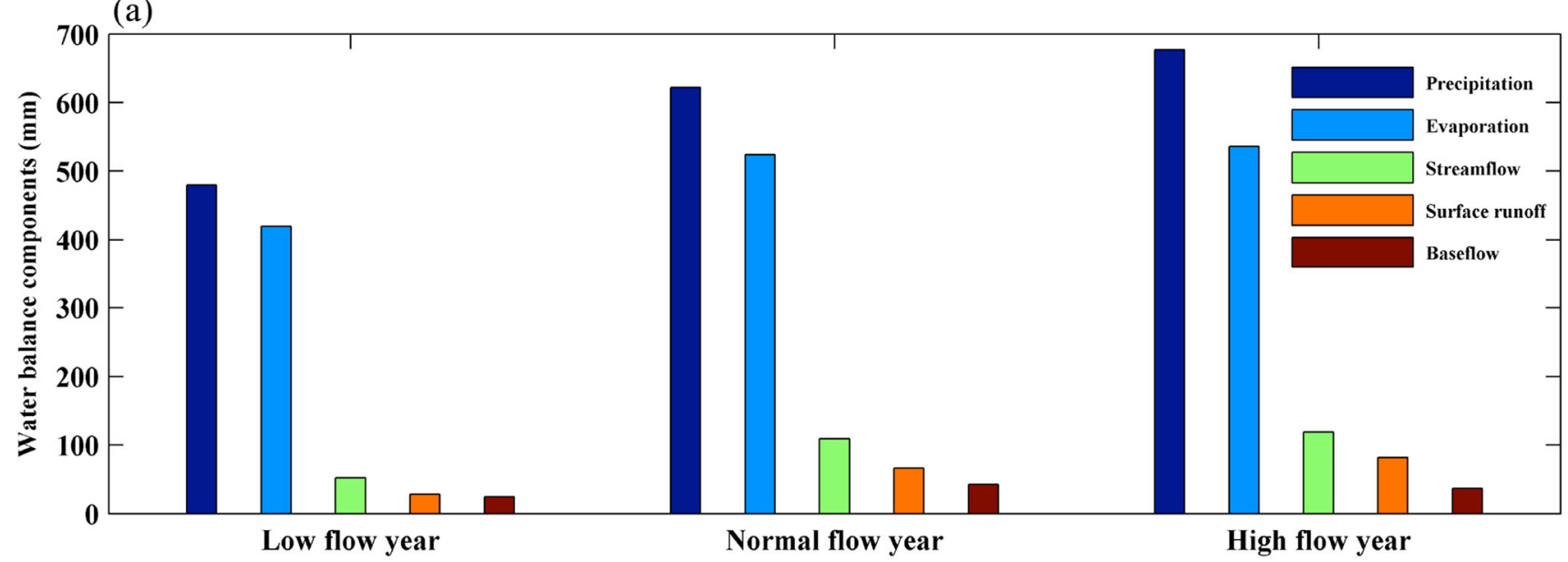

(b)

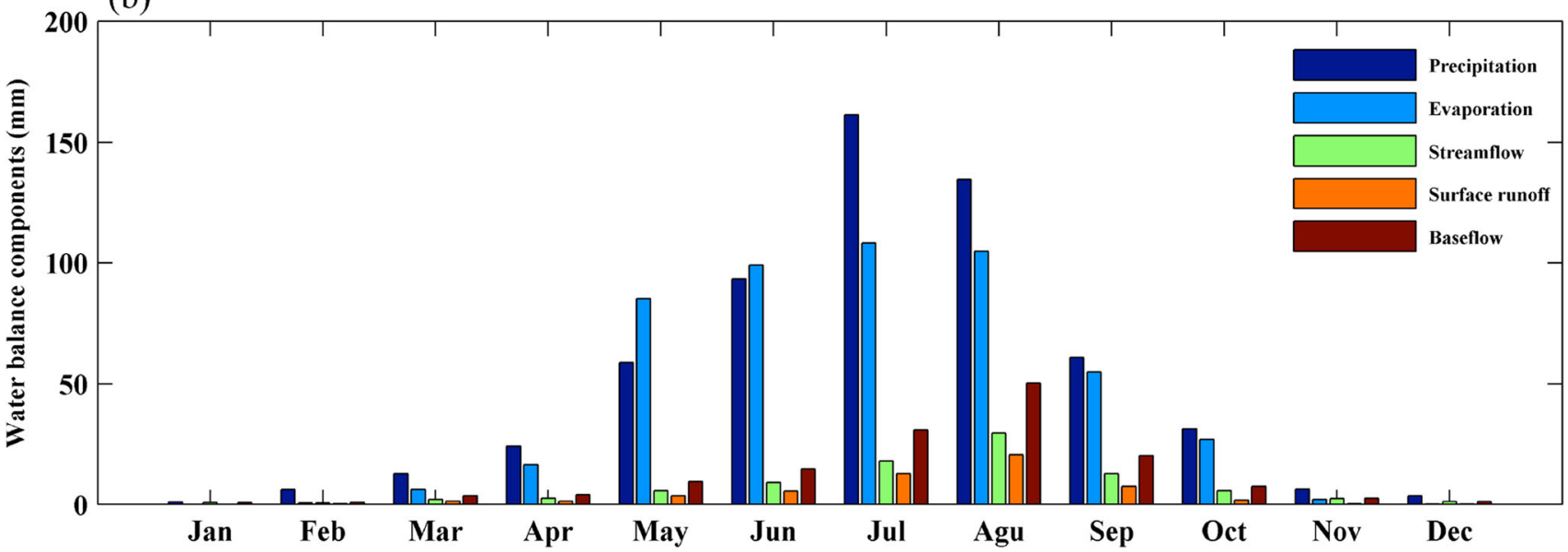

Figure 5. Water balance components for different seasons and hydrological years. 
evapotranspiration) of the GWLF model simulation are presented in Fig. 5b. As can be seen from Fig. 5b, it was apparent that the high values of the water balance variables occurred during the flood season, especially in July and August. The rainfall, streamflow, surface runoff, and baseflow of the flood season accounted for 75.7, $76.3,84.2$, and $64.3 \%$ of the annual amount. Thus, the centralized rainfall events during the flood season in the Liu River watershed [20] which can export large amounts of nutrient loads were the reason for the higher percentage of NPS loads in the same period.

\subsection{Spatial Distribution of NPS Load and Identification of CSAs}

Mean annual NPS loads from the 18 sub-watersheds are given in Tab 1. In the Liu River watershed, the annual TN NPS load was 594.2 ton/year, while annual TP NPS load was much smaller, 44.5 ton/year. The NPS loads and proportions of total load varied considerably among different sub-watersheds. For example, subwatershed 18 was the largest sub-watershed and acted as the largest contributor to the watershed TP load $(10.7 \%)$ and the second largest contributor to the watershed TN load (10.0\%). While subwatershed 17, which was the second largest sub-watershed, contributed the largest part of watershed TN load $(10.9 \%)$ and the second largest part of the watershed TP load (10.4\%). Subwatersheds 6 and 16, which respectively had the 6th and 7th largest areas, were the other major contributors to watershed NPS TN and TP loads.

The CSAs for NPS load were investigated at the sub-watershed level. Figure 6 shows the simulated annual average NPS nutrient load intensities for 18 sub-watersheds. The TN load intensity could reach as high as $7.09 \mathrm{~kg} / \mathrm{ha} /$ year in sub-watershed 15 , whereas the TP load intensity could be as high as $0.57 \mathrm{~kg} / \mathrm{ha} / \mathrm{year}$ in subwatershed 7. Load intensities $(\mathrm{kg} / \mathrm{ha})$ and collectively percentage $(\%)$ of the TN and TP NPS loads for CSAs identification are shown in Tab 2. Based on the $30 \%$ threshold, five sub-watersheds including

Table 1. Mean annual nutrient NPS loads and relative contributions of total load for 18 sub-watersheds

\begin{tabular}{|c|c|c|c|c|c|}
\hline \multirow[b]{2}{*}{ Sub-watershed } & \multirow[b]{2}{*}{$\begin{array}{l}\text { Area } \\
\left(\mathrm{km}^{2}\right)\end{array}$} & \multicolumn{2}{|c|}{$\mathrm{TN}$} & \multicolumn{2}{|c|}{$\mathrm{TP}$} \\
\hline & & $\begin{array}{c}\text { Load } \\
\text { (ton/year) }\end{array}$ & $\begin{array}{c}\text { Percentage } \\
(\%)\end{array}$ & $\begin{array}{c}\text { Load } \\
\text { (ton/year) }\end{array}$ & $\begin{array}{c}\text { Percentage } \\
(\%)\end{array}$ \\
\hline 1 & 32.4 & 17.6 & 3.0 & 1.3 & 2.9 \\
\hline 2 & 124.0 & 34.0 & 5.7 & 2.4 & 5.3 \\
\hline 3 & 82.9 & 31.6 & 5.3 & 2.4 & 5.4 \\
\hline 4 & 42.9 & 18.6 & 3.1 & 1.4 & 3.2 \\
\hline 5 & 104.7 & 42.6 & 7.2 & 3.3 & 7.3 \\
\hline 6 & 79.4 & 46.9 & 7.9 & 3.5 & 7.9 \\
\hline 7 & 33.6 & 19.7 & 3.3 & 2.0 & 4.6 \\
\hline 8 & 32.4 & 14.8 & 2.5 & 1.1 & 2.5 \\
\hline 9 & 58.9 & 19.2 & 3.2 & 1.2 & 2.6 \\
\hline 10 & 61.5 & 29.5 & 5.0 & 2.1 & 4.8 \\
\hline 11 & 61.4 & 38.9 & 6.5 & 3.0 & 6.7 \\
\hline 12 & 30.4 & 17.8 & 3.0 & 1.4 & 3.0 \\
\hline 13 & 42.5 & 24.6 & 4.1 & 1.8 & 4.0 \\
\hline 14 & 51.4 & 32.9 & 5.5 & 2.5 & 5.6 \\
\hline 15 & 41.8 & 31.4 & 5.3 & 2.0 & 4.5 \\
\hline 16 & 72.3 & 49.6 & 8.4 & 3.8 & 8.5 \\
\hline 17 & 104.8 & 64.9 & 10.9 & 4.6 & 10.4 \\
\hline 18 & 111.8 & 59.5 & 10.0 & 4.8 & 10.7 \\
\hline Total & 1169.0 & 594.2 & 100.0 & 44.5 & 100.0 \\
\hline
\end{tabular}
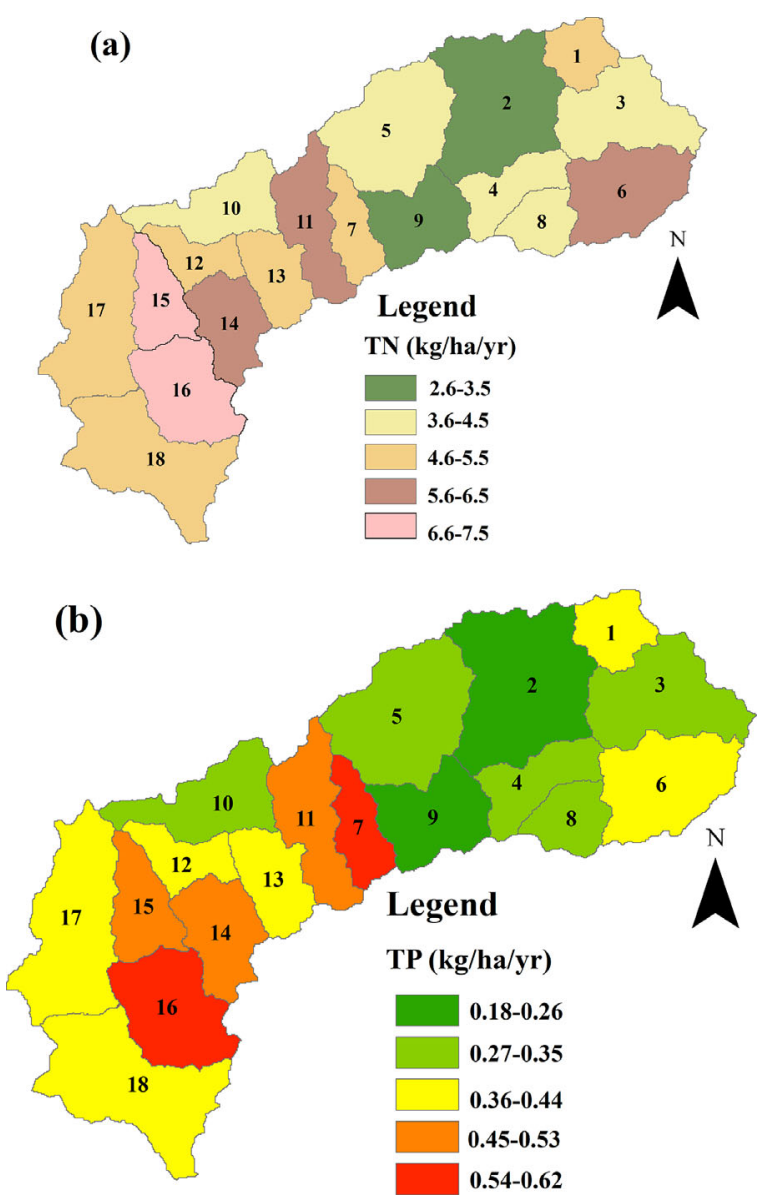

Figure 6. Spatial distribution of annual average nutrient loads on the subwatershed level.

$\# 15$, \#16, \#14, \#11, and \#6 which covered $26 \%$ of the watershed area were identified as TN CSAs. Five sub-watersheds, which included sub-watersheds $7,16,11,14$, and 15 covering $22 \%$ of the watershed area, were identified as TP CSAs. Sub-watersheds 16, 11, 14 , and 15 were identified as CSAs for both TN and TP loss. However, sub-watershed 6 was identified as TN CSAs, and sub-watershed 7 was identified as TP CSAs. Taking account of synthetic factors for TN and TP, sub-watersheds $16,11,14$, and 15 were identified as nutrient NPS pollution CSAs, accounting for 26 and $25 \%$ of TN and TP NPS loads.

It could be shown that CSAs with high level of nutrient load intensities presented relatively high percentage of agricultural land and residential land. The agricultural lands were farmland and orchard, and the residential lands were rural village and urban area.

Table 2. Load intensities (kg/ha) and collectively percentage (\%) of total NPS loads for CSAs identification

\begin{tabular}{lcrrrr}
\hline Sub-watershed & $\begin{array}{c}\mathrm{TN} \\
(\mathrm{kg} / \mathrm{ha})\end{array}$ & $\begin{array}{c}\text { Collectively } \\
(\%)\end{array}$ & $\begin{array}{c}\text { Sub- } \\
\text { watershed }\end{array}$ & $\begin{array}{c}\mathrm{TP} \\
(\mathrm{kg} / \mathrm{ha})\end{array}$ & $\begin{array}{c}\text { Collectively } \\
(\%)\end{array}$ \\
\hline 15 & 7.52 & 5.3 & 7 & 0.61 & 4.6 \\
16 & 6.86 & 13.6 & 16 & 0.52 & 13.1 \\
14 & 6.40 & 19.2 & 11 & 0.49 & 19.9 \\
11 & 6.33 & 25.7 & 14 & 0.49 & 25.5 \\
6 & 5.91 & 33.6 & 15 & 0.48 & 30.0 \\
\hline
\end{tabular}


Table 3. Load intensities $(\mathrm{kg} / \mathrm{ha})$ and contribution ratio of total NPS loads for different land uses

\begin{tabular}{lccccc}
\hline & \multicolumn{2}{c}{ TN } & & \multicolumn{2}{c}{ TP } \\
\cline { 2 - 3 } \cline { 5 - 6 } Land use & $\begin{array}{c}\text { Load } \\
\text { intensity }\end{array}$ & $\begin{array}{c}\text { Ratio } \\
(\%)\end{array}$ & & $\begin{array}{c}\text { Load } \\
\text { intensity }\end{array}$ & $\begin{array}{c}\text { Ratio } \\
(\%)\end{array}$ \\
\hline Orchard & 14.80 & 29.4 & & 1.13 & 29.2 \\
Farmland & 17.75 & 18.6 & & 1.28 & 17.9 \\
Grassland & 4.84 & 19.9 & & 0.49 & 26.9 \\
Forest & 2.06 & 27.2 & & 0.11 & 19.4 \\
Residential land & 9.58 & 5.0 & & 0.96 & 6.7 \\
\hline
\end{tabular}

These land uses represented the anthropogenic nutrients input to the watershed compared to forest and grassland. Load intensities $(\mathrm{kg} / \mathrm{ha})$ and collectively percentage (\%) of TN and TP NPS load for CSAs identification are shown in Tab 3. As can be seen from Tab 3, the load intensities of agricultural land and residential land were much higher than of forest and grassland. Therefore, subwatersheds with high percentage of agricultural land and residential land had high load intensities, and were identified as CSAs. The orchard accounting for only $9.8 \%$ of total watershed area was the largest source of TN and TP NPS loads because of the highest load intensities. The farmland accounting for only $5.7 \%$ of total watershed area contributed 18.6 and $17.9 \%$ of the TN and TP NPS loads. The residential land was the lowest source of NPS load due to the small percentage of the total watershed. To further investigate the relationship between NPS CSAs and land use, the land use composition of the CSAs was investigated. As shown in Tab 4, the CSAs had much higher percentages of farmland, orchard or residential land than the watershed average. This finding was consistent with that of Niraula et al. [19] who reported that sub-watersheds dominated by urban area were among those producing highest amount of nutrient loads and were identified as CSAs in Saugahatchee Creek watershed, USA. In addition, $\mathrm{Wu}$ and Chen [21] found that sub-watersheds with a high percentage of agricultural land were identified as CSAs in the Donghe watershed, China.

\subsection{Implications for NPS Pollution Mitigation Measures}

The findings of temporal distribution and CASs for nutrient load have important implications for developing mitigation measures for nutrient pollution. The results of the GWLF model indicated that NPS pollution was the major source of nutrient load in the Liu River watershed, accounting for 81.8 and $92.5 \%$ of the TN and TP load. The conventional pollution load allocation programs in China considered the contribution of point sources using a constant flow under critical condition, typically using the $7 \mathrm{Q} 10$ (the annual minimum seven days average streamflow with a ten years recurrence interval) low flow condition. The NPS loads were usually not incorporated in the conventional program, making it not appropriate for the watershed with high percentage of NPS load, such as Liu River watershed. Therefore, it is necessary to consider the contribution of NPS pollution to the total load in the load allocation programs for Liu River watershed. Moreover, the contributions of NPS pollution to the TN load varied greatly among flood and non-flood seasons, suggesting the necessity to adjust priority actions according to the seasonal changes. For instance, measures for nutrient load reduction in the flood season should focus on NPS pollution because NPS nutrient loads were mainly exported by the high flows during the flood season. While in the non-flood season, priority actions should be undertaken to control point source pollution as water quality responds primarily to point sources in this season.

Because of the high contribution of NPS pollution load, BMPs for reducing NPS pollution are urgently needed to protect water quality in Liu River watershed. Broadly speaking, BMPs are structural and non-structural approaches used to reduce pollutant loads in the watershed. In this study, six agricultural BMPs and one streamrelated BMP (Tab 5) were selected from the pollution reduction impact comparison tool (PRedICT) [22] and the reduction efficiency and per unit implementation cost for each BMP were from PRedICT. As CSAs have the great potential on NPS pollution reduction, the implement of BMPs in these sub-watersheds could improve the efficiency of pollution reduction. BMP1, BMP2, BMP3, and BMP4 were implemented in the farmland of CSAs sub-watersheds.

Table 4. Land use composition of the CSAs in Liu River watershed

\begin{tabular}{|c|c|c|c|c|c|c|}
\hline Sub-watershed \# & Farmland (\%) & Orchard (\%) & Grassland (\%) & Forest (\%) & Residential land (\%) & Water $(\%)$ \\
\hline 11 & 11.9 & 7.6 & 13.8 & 54.6 & 10.3 & 1.8 \\
\hline 14 & 15.7 & 5.5 & 6.9 & 57.6 & 11 & 2.6 \\
\hline 15 & 5.6 & 16.9 & 28.6 & 48 & 0 & 0.9 \\
\hline 16 & 10.3 & 14.5 & 19.4 & 48.4 & 5.9 & 1.5 \\
\hline
\end{tabular}

Table 5. Estimated BMP reduction efficiency (\%) and unite cost*

\begin{tabular}{|c|c|c|c|c|}
\hline \multirow[b]{2}{*}{ Number } & \multirow[b]{2}{*}{ Description } & \multicolumn{2}{|c|}{ Reduction efficiency (\%) } & \multirow[b]{2}{*}{ Unite cost } \\
\hline & & $\mathrm{TN}$ & $\mathrm{TP}$ & \\
\hline BMP1 & Cropland protection & 25 & 36 & $\$ 50 /$ acre \\
\hline BMP2 & Conservation tillage & 50 & 38 & $\$ 30 /$ acre \\
\hline BMP3 & Strip cropping/contour farming & 23 & 40 & $\$ 10 /$ acre \\
\hline BMP4 & Terraces and diversions & 44 & 42 & $\$ 500 /$ acre \\
\hline BMP5 & Nutrient management & 70 & 28 & $\$ 110 /$ acre \\
\hline BMP6 & Agriculture to forest land conversion & 95 & 94 & $\$ 5000 /$ acre \\
\hline BMP7 & Vegetative buffers & 64 & 52 & $\$ 1500 /$ mile \\
\hline
\end{tabular}

*Estimated BMP reduction efficiency (\%) and unite cost from PRedICT 
Table 6. Reduction efficiency (\%) and cost for different individually used BMPs

\begin{tabular}{|c|c|c|c|c|c|c|c|c|}
\hline & & BMP1 & BMP2 & BMP3 & BMP4 & BMP5 & BMP6 & BMP7 \\
\hline \multirow[t]{2}{*}{ Load reduction (ton) } & $\mathrm{TN}$ & 11 & 22.1 & 10.1 & 19.4 & 84.5 & 114.7 & 88.1 \\
\hline & $\mathrm{TP}$ & 1.1 & 1.2 & 1.3 & 1.3 & 2.5 & 8.3 & 4.8 \\
\hline \multirow{2}{*}{ Reduction ratio (\%) } & $\mathrm{TN}$ & 1.9 & 3.7 & 1.7 & 3.3 & 14.2 & 19.3 & 14.8 \\
\hline & $\mathrm{TP}$ & 2.5 & 2.7 & 2.9 & 2.9 & 5.6 & 18.7 & 10.8 \\
\hline Cost $\left(10^{4} \$\right)$ & & 21.6 & 13.0 & 4.3 & 216 & 138.1 & 6279 & 3.5 \\
\hline
\end{tabular}

Moreover, BMP5, BMP6, and BMP7 were implemented in the farmland and orchard of CSAs sub-watersheds. Because orchard is another agricultural land in Liu River watershed, and BMP5, BMP6, and BMP7 can reduce the loads from orchard. The reduction loads of different BMPs were evaluated by GWLF model simulation results and the BMP reduction efficiencies are given in Tab 5. For example, the nutrient load reduction was calculated through multiplying the BMP reduction efficiency by the farmland loads of four CSAs sub-watersheds. The nutrient loads from farmland in CSAs subwatersheds were determined from the GWLF model simulation. The BMPs were implemented for the CSAs sub-watersheds, and the reduction efficiencies (\%) and the costs for different BMPs when individually used in CSAs were evaluated first (Tab 6). As can be seen from Tab 6, BMP6 has the most reduction efficiency, whereas it has the highest cost. Considering the high cost, BMP6 was not selected as the measure for Liu River watershed. Among the different BMPs, BMP7 was the most cost-effective step, as it has the second largest reduction efficiency and the minimal cost. Therefore, BMP7 was selected as NPS control measure for Liu River watershed. For other BMPs, BMP5 has relatively high reduction efficiency with high cost, and BMP5 were not selected considering the cost. From BMP1 to BMP4, they have comparative reduction efficiencies with different costs, and BMP2 was selected considering the cost reduction efficiencies. Therefore, BMP2 (conservation tillage) can be combined with BMP7 (vegetative buffers) to represent NPS pollution management practices in the Liu River watershed. The reduction loads of combined BMPs were 84.4 and 5.6 ton for TN and TP, accounting for 14.2 and $12.5 \%$ of TN and TP NPS loads in the Liu River watershed.

\section{Conclusions}

The GWLF model was applied to simulate streamflow and nutrient load in the Liu River watershed, northern China. The temporalspatial distribution, the CSAs at sub-watershed level, and the BMP efficiencies at CSAs were investigated based on the model results. The temporal distribution of NPS loads showed obvious inter-annual and seasonal variability. For instance, the annual NPS load concentrated in flood season, which indicated that measures for nutrient load reduction in the flood season should be focused on NPS pollution. Four sub-watersheds with high percentages of agricultural or residential land were identified as nutrient NPS pollution CSAs, accounting for 26 and $25 \%$ of TN and TP NPS loads. Through evaluating the efficiency and cost for seven BMPs, conservation tillage and vegetative buffers were selected as the measures to implement in the CSAs, and they can reduce 14.2 and $12.5 \%$ of TN and TP NPS loads in Liu river watershed. The BMPs evaluation here was the preliminary assessment, and further investigations are needed to establish a multi-optimization procedure for placing cost effective BMPs at the watershed scale to achieve the water quality goal. The model-based evaluation for watershed NPS pollution in this study can provide useful information to help design the nutrient NPS load reduction programs and offer valuable information for the local decision-makers to develop reasonable management measures controlling watershed NPS pollution. In conclusion, this study demonstrates that the relatively parsimonious GWLF model can provide reliable evaluation for watershed NPS pollution with modest input data requirements, and as such is a useful tool in NPS pollution management, especially for the watersheds with limited datasets.

\section{Acknowledgments}

Funding was provided by the Chinese Academy of Sciences' key project (KZZD-EW-10-02), RCEES “One-Three-Five” project (YSW2013B02-4), and the key laboratory project from the State Key Laboratory of Urban and Regional Ecology, RCEES, CAS (SKLURE2013-1-05). The authors thank the Chengde Branch of Hebei Provincial Survey Bureau of Hydrology and Water Resources for providing the hydrological and water quality data.

The authors have declared no conflict of interest.

\section{References}

[1] W. L. Duan, K. Takara, B. He, P. P. Luo, D. Nover, Y. Yamashiki, Spatial and Temporal Trends in Estimates of Nutrient and Suspended Sediment Loads in the Ishikari River, Japan, 1985 to 2010, Sci. Total Environ. 2013, 461, 499-508.

[2] Y. Han, Y. Fan, P. Yang, X. Wang, Y. Wang, J. Tian, L. Xu, et al. Net Anthropogenic Nitrogen Inputs (NANI) Index Application in Mainland China, Geoderma 2014, 213, 87-94.

[3] Y. Han, X. Yu, X. Wang, Y. Wang, J. Tian, L. Xu, C. Wang, Net Anthropogenic Phosphorus Inputs (NAPI) Index Application in Mainland China, Chemosphere 2013, 90 (2), 329-337.

[4] J. Y. Jiang, S. Y. Li, J. T. Hu, J. Huang, A Modeling Approach to Evaluating the Impacts of Policy-induced Land Management Practices on Non-Point Source Pollution: A Case Study of the Liuxi River Watershed, China, Agric. Water Manage. 2014, 131, 1-16.

[5] E. D. Ongley, X. L. Zhang, T. Yu, Current Status of Agricultural and Rural Non-Point Source Pollution Assessment in China, Environ. Pollut. 2010, 158 (5), 1159-1168.

[6] L. Wu, T. Y. Long, W. J. Cooper, Simulation of Spatial and Temporal Distribution on Dissolved Non-Point Source Nitrogen and Phosphorus Load in Jialing River Watershed, China, Environ. Earth Sci. 2012, 65 (6), 1795-1806.

[7] Z. Y. Shen, Q. Hong, Z. Chu, Y. W. Gong, A Framework for Priority Non-Point Source Area Identification and Load Estimation Integrated with APPI and PLOAD Model in Fujiang Watershed, China, Agric. Water Manage. 2011, 98 (6), 977-989.

[8] Y. Chen, J. B. Shuai, Z. Zhang, P. J. Shi, F. L. Tao, Simulating the Impact of Watershed Management for Surface Water Quality Protection: A Case Study on Reducing Inorganic Nitrogen Load at a Watershed Scale, Ecol. Eng. 2014, 62, 61-70. 
[9] P. Strauss, A. Leone, M. N. Ripa, N. Turpin, J. M. Lescot, R. Laplana Using Critical Source Areas for Targeting Cost-Effective Bes Management Practices to Mitigate Phosphorus and Sediment Transfer at the Watershed Scale, Soil Use Manage. 2007, 23, 144-153.

[10] L. Wu, T. Y. Long, C. M. Li, The Simulation Research of Dissolved Nitrogen and Phosphorus Non-Point Source Pollution in Xiao-Jiang Watershed of Three Gorges Reservoir Area, Water Sci. Technol. 2010, 61 (6), 1601-1616.

[11] R. Niraula, L. Kalin, P. Srivastava, C. J. Anderson, Identifying Critical Source Areas of Nonpoint Source Pollution with SWAT and GWLF, Ecol. Modell. 2013, 268, 123-133.

[12] R. M. Liu, P. P. Zhang, X. J. Wang, Y. X. Chen, Z. Y. Shen, Assessment of Effects of Best Management Practices on Agricultural Non-Point Source Pollution in Xiangxi River Watershed, Agric. Water Manage. 2013, 117, 9-18.

[13] J. Sha, M. Liu, D. Wang, D. P. Swaney, Y. Q. Wang, Application of the ReNuMa Model in the Sha He River Watershed: Tools for Watershed Environmental Management, J. Environ. Manage. 2013, $124,40-50$.

[14] J. Tu, Combined Impact of Climate and Land Use Changes on Streamflow and Water Quality in Eastern Massachusetts, USA, J. Hydrol. 2009, 379 (3-4), 268-283.

[15] D. A. Haith, L. L. Shoemaker, Generalized Watershed Loading Functions for Stream-Flow Nutrients, Water Resour. Bull. 1987, 23 (3), 471-478.
[16] X. Z. Du, X. Y. Li, W. S. Zhang, H. L. Wang, Variations in Source Apportionments of Nutrient Load Among Seasons and Hydrological Years in a Semi-Arid Watershed: GWLF Model Results, Environ. Sci. Pollut. Res. 2014, 21 (10), 6506-6515.

[17] X. Y. Li, D. E. Weller, T. E. Jordan, Watershed Model Calibration Using Multi-Objective Optimization and Multi-Site Averaging, J. Hydrol. 2010, 380 (3-4), 277-288.

[18] X. Shang, X. Z. Wang, D. L. Zhang, W. D. Chen, X. C. Chen, H. N. Kong, An Improved SWAT-Based Computational Framework for Identifying Critical Source Areas for Agricultural Pollution at the Lake Basin Scale, Ecol. Modell. 2012, 226, 1-10.

[19] R. Aguilera, R. Marce, S. Sabater, Linking In-Stream Nutrient Flux to Land Use and Inter-Annual Hydrological Variability at the Watershed Scale, Sci. Total Environ. 2012, 440, 72-81.

[20] X. Z. Du, X. Y. Li, S. N. Hao, H. L. Wang, X. Shen, Contrasting Patterns of Nutrient Dynamics During Different Storm Events in a Semi-Arid Catchment of Northern China, Water Sci. Technol. 2014, 69 (12), 2533-2540.

[21] Y. P. Wu, J. Chen, Investigating the Effects of Point Source and Nonpoint Source Pollution on the Water Quality of the East River (Dongjiang) in South China, Ecol. Indic. 2013, 32, 294-304.

[22] B. M. Evans, D. W. Lehning, K. J. Corradin, Users Guide for the Pollutant Reduction Impact Comparison Tool (PRedICT), Version 7.1, Penn State Institutes of Energy and the Environment. The Pennsylvania State University, University Park, PA, USA 2008. 